\title{
PREFERRED ADAPTIVE STRATEGIES \\ AN APPROACH TO UNDERSTANDING NEW ZEALAND'S MULTI-CULTURAL WORKFORCE
}

\author{
NANCY B. GRAVES and THEODORE D. GRAVES*
}

\section{ABSTRACT}

This article examines the effect of cultural background on the choice of adaptive strategies which various workers employ for dealing with life. A worker's preference among alternative strategies has relevance for many aspects of his work motivation, attitudes and behaviour on the job. The relevance of alternative strategy types for management is discussed and illustrated, and a brief measure of Preferred Adaptive Strategy is provided which can be administered to prospective employees.

\section{INTRODUCTION}

Many aspects of a worker's background, personality and situation influence his or her behaviour on the job. Each worker presents a unique combination of such factors as age, sex, family situation, experience, etc. Furthermore, each department has its own particular physical layout, task organisation and personnel which influence the performance of its members. All of these interacting factors need to be considered by management when developing policies aimed at maximizing the efficiency, output, and job satisfaction of its workers. New Zealand managers, however, face further complexity because of the variety of national backgrounds represented within their multicultural work force.

One management response to this complexity is simply to treat every worker alike, requiring all to adjust to a single set of institutional requirements. This is unfair to those workers whose temperament and life style differ. It also fails to take advantage of the special contribution which they may make to management's own production goals. At the other extreme, management may treat each worker as unique, helping him or her to perform well over years of mutual accommodation. But this approach is probably feasible only in small firms, and does not permit predictive selection and placement of new workers to maximize their satisfaction and productivity. Our aim is to simplify without over-simplification, to draw attention to some important implications of cultural background while at the same time helping us each to remember that not all members of a particular national group will think and act in similar, stereotypic ways. Our focus here will be on two broad worker characteristics which we have found particularly helpful for better understanding a variety of work-relevant attitudes and behaviour: ethnic status and preferred adaptive strategy. 'Ethnicity' summarizes a variety of background experiences which most members of a culture group are likely to share; 'adaptive strategy' summarizes many behavioural patterns which a person has developed for coping with the problems of daily life. Both also imply characteristic motivational states which grow out of common experience and underlie habitual coping behaviour.

\section{ETHNICITY}

New Zealand is a country of immigrants. Differences in race and culture have therefore impinged on our sensitivities long enough to become a standard part of our folk wisdom. Some of this wisdom is useful, some is no more than stereotype, prevent-

\footnotetext{
- DR NANCY B. GRAVES and DR THEODORE D. GRAVES, of the South Pacific Research Institute Incorporated, Auckland New Zealand, are currently at the Center for Advanced Study in the Behavioral Sciences, Stanford, California. This article is based on a six-month exploratory research proiect conducted by the authors under a grant from the Polynesian Advisory Committee of the Vocational Training Council whose support throughout this work the authors acknowledge with appreciation. During the project interviews were conducted with management representatives in over thirty factories, followed by systematic, in-depth interviews with 157 floor-level production workers in two contrasting carpet mills. A lengthy report on this work, "Understanding New Zealand's Multicultural Workforce," is available through the Vocational Training Council. The authors also wish to thank the Center for Advanced Study in the Behavioral Sciences, Stanford, Callifornia, U.S.A. and the National Science Foundation (BNS-76-22943) for providing a fellowship year during which this article could be written.
} 
ing us from reacting to people in a more differentiated, predictive and humane manner. In approaching a better understanding of New Zealand's multicultural work force, however, ethnicity is a good place to begin, as long as we recognise that it is only a beginning.

It seems obvious to suggest that persons belonging to different cultural traditions may differ in their attitudes toward work and their ways of behaving on the job. People who grow up within the same or closely related cultural traditions share many background experiences which give them a body of common values and attitudes. Most of us know, for example, that Polynesians, whether Maoris or Samoans, Cook Islanders or Niueans, are apt to have grown up in larger families than the average New Zealander of European extraction, and families in which a variety of relatives have played significant roles. The implications of such facts for work-relevant attitudes and behaviour, however, are not always so well appreciated.

Here it is useful to make explicit a distinction between ethnic or cultural tradition and 'race.' New Zealanders commonly use the two terms interchangeably, but this can be a source of confusion and misunderstanding. The first refers to social inheritance, the second to biological inheritance. A Maori brought up in a European home may be racially Polynesian but culturally European. A Pacific Islander brought up in New Zealand and attending New Zealand schools has acquired a cultural tradition in many ways different from that of his biological brothers raised in the islands.

On the basis of our research we have found it useful to distinguish three broad ethnic categories. The first, Europeans, refers to New Zealanders of an English cultural background. including (in our sample) migrants from both England and Australia as well as those born in New Zealand. Obviously there are many differences between immigrants and native-born white New Zealanders, even if all have a common British heritage. Nevertheless, they share a large body of work-relevant attitudes and values.

The second broad category we refer to as New Zealand Educated Polynesians. In this we include indigenous Maoris and those from a variety of Island nations who were born in New Zealand or who came here as school children. Although social distinctions may be retained among them, Pacific Islanders, regardless of their cultural origins, come to share many common values with Maoris when they have received at least part of their formal education in New Zealand, and have been subjected as children to the experience of minority group status.

Finally, we will group together those workers from various Pacific Island communities who have migrated to New Zealand as adults into a larger category of Pacific Island Immigrants. Samoans and Cook Islanders constitute the majority of these, but Tongans, Niueans, and Tokelau Islanders should be included as well. ${ }^{1}$ Again, there are obvious and important differences among these various culture groups. But in this article we will focus on shared characteristics which differentiate Island immigrant workers from those in the other two major ethnic categories.

It is important for managers to recognise from the outset that the members of each ethnic category are in no sense homogeneous. They share many work-relevant attributes which makes the three broad ethnic categories we have distinguished here a useful first step in differentiating among workers. But within each category there are important differences. Some of these differences have their origin in the specific cultural background of the worker: Samoan, Tongan, and so forth. For many purposes, however, management may find it more useful to differentiate among workers not on the basis of the national tradition to which they belong, but by the type of adaptation which each has chosen to make to New Zealand life.

\section{PREFERRED ADAPTIVE STRATEGY}

In coping with the world around him, each individual has a variety of alternative resources which he can call upon: his own, those of the 'nuclear' family which he has founded (consisting only of parents and their children), those of his 'extended' family (the broader circle of kinsmen), those of his friends and neighbours, and those of the wider society, as provided through more impersonal agencies and in-

1-In this article we are dealing only with Polynesian Pacific Islanders, although we recognise that Fijians. Indians, etc, are immigrants from the Pacific Islands as well. Members of these groups were not included
in our samples. 
stitutions. We will refer to a person's choice among these alternative resources, and the associated behaviour which this choice entails, as his adaptive strategy.

Each person differs in the extent of his own resources, and in his access to and knowledge of the resources available to rim elsewhere. People also differ in their predilection for one or another of these resource locations, both from habits of cultural tradition and personal history, and from the costs which using each type of resource entail. Consequently, although most people draw upon resources from all these locations at different times and for different purposes, they can usually be characterized by the predominant resource centre to which they turn.

We will make a distinction between three principle adaptive strategies: KinReliance, Peer-Reliance, and Self-Reliance. In Kin-Reliance the individual typically calls on resources of the wider circle of relatives beyond his nuclear family, in Peer-Reliance he turns to persons of roughly his own generation and social standing, whereas in Self-Reliance he depends on his own resources, those of his nuclear household, or the impersonal institutions of the wider society.

To be an effective adaptation, KinReliance requires the presence of a reasnnably large number of relatives with access to a variety of resources: when you want to buy a house, if your uncle is a solicitor you can turn to him for legal help: when you want to fix your car, if your cousin is a panelbeater he can be asked to lend a hand. If you have expertise of your own, you will be expected to reciprocate. At the very least you must maintain a good 'name' within your family, a reputation for willingness to help when called upon, for contributing to and attending family functions, supporting family members in conflicts with outsiders, feeding and housing relatives when they come to visit or to live in your community, giving deference and respect to elders when family decisions are being made. In other words, if you want to count on your family in times of need, they in turn must be able to count on you. This can become quite costly and burdensome at times.

Peer-Reliance has many of the same advantages as Kin-Reliance in providing a wide circle of people with different skills and access to a variety of resources. One of our friends can 'get it for us wholesale,' another will do the job at 'mate's rates.' To be effective, this adaptation requires a wide communication network to put a person in touch with what resources are available through friendship channels. This is one of the important latent functions of going to the pub, playing football, or attending any other social function. As with Kin-Reliance, there are obvious costs in time and money: Peer-Reliant people must keep their social net widespread and in good repair. And the structure may be less dependable than kinship in the crunch. We have all experienced the 'fair-weather friend,' and neighbours come and go. Consequently, accounts tend to be settled on a more short-term basis, and some investments bear no return. By contrast, KinReliant investments in the wider family can almost always be drawn on with interest far into the future.

A Self-Reliant strategy has its own risks and penalties. Goods and services cost substantially more money, so it either requires a higher income or offers a lower standard of living. And the Self-Reliant Derson must go to the trouble of informing himself as to what resources public agencies offer, and accept the insensitivity and impersonality of the services they provide. The psychological penalties of SelfReliance may also be high, on both the individuai and his immediate family. On the other hand, you can 'count on yourself,' and avoid the potential inconvenience of outside calls on your time and energy.

An emphasis on one or another of these adaptations tends to require and to foster certain distinctive traits of character, which have implications for employers when understanding worker job performance. Both Kin-Reliant and Peer-Reliant people tend to be group-oriented, often with stronger interests in their workmates than in their tasks. They are generally cooperative and helpful, friendly and goodhumoured. They like to work in groups, feel comfortable in groups, and gain major rewards in life from their social roles. They also tend to be more subject to group norms and pressures than people who have chosen a Self-Reliant adaptation; these norms and pressures may either support or be at variance with company goals.

Kin-Reliant persons have had to learn to accept the authority of their elders and family leaders, whereas Peer-Reliant per- 
sons are more apt to be strongly egalitarian, often resenting any display of authority. Self-Reliant people may be even more individualistic, guarding their autonomy with jealousy. They are apt to be more competitive and more motivated by rewards of personal achievement, self-improvement. recognition and power. These strong habits of competition and rivalry may be hard to overcome when the situation calls for teamwork and co-operative effort.

\section{ETHNICITY AND PREFERRED ADAPTIVE STRATEGY}

Ethnic groups differ in the emphasis they tend to place on one or another of these three strategies. Traditionally, Polynesian people draw upon the resources available through the interdependent kin networks in which they grow up and live out their lives. The extended family nurtures the virtues of generosity, co-operation and hospitality. Whatever goods one has, one shares, and since the family is large there is little fear of going without on the morrow. Consequently, Kin-Reliance is a well-estabilished adaptation to life, and when migrant Pacific Islanders arrive in New Zealand with few personal resources and many new problems to cope with, it is the obvious and overwhelmingly chosen strategy.

Polynesians, however, also have a strong cultural predilection for a Peer-Reliant adaptation. The Polynesian child, whether Maori or Pacific Islander, usually grows up within a wide circle of caretakers, many of whom are other children. Almost as soon as they can walk, Polynesian children are given responsibility for the care of their younger brothers, sisters and cousins, and this responsibility increases with age. They join a neighbourhood play group which wanders freely together (since the village environment is usually quite safe) almost from the time they can toddle. It is to this group of friends and relations within the same generation that the individual turns when adult authority seems unbearably strong.

As society has changed and more and more Polynesian families have come to the city, the Peer-Reliant pattern is one which has been easy for younger members of the family to adopt, particularly as they acquire a wider circle of mates in school and on the job. It fosters the virtues of comradeship, sharing, and egalitarianism - an atmosphere where all help each other but no one tells another just what to do or how to do it unless asked for help. Very important to this adaptation is acceptance of another's particular personality, an easygoing tolerance, and the development of social skills, such as joking and the ability to take teasing, which can prevent or deflect disagreements or rifts within the group.

With the spread of Western education, a money economy, and the independent life these make possible, a Self-Reliant strategy is increasingly being adopted by some Polynesians even when living in remote island communities. This option is facilitated by certain social conditions, however, and these are more common in New Zealand than in the islands: impersonal social agencies are more readily available here, incomes are higher, and 'state houses' and building codes tend to separate families into small parent-child households. As their own competence to cope with New Zealand society grows, therefore, Self-Reliance becomes increasingly attractive to migrants who may find the demands of their kin or peer group too time-consuming or burdensome.

The predominance of small families and a Western system of education with its emphasis on individual achievement and competition has laid a cultural foundation for the Self-Reliant strategy within European society, and this is the adaptation assumed by the majority under most circumstances. This adaptation is reinforced by social and geographic mobility, particularly among more affluent families. But we must not forget the strong current of mate-ship and egalitarianism on which Kiwis pride themselves, the popularity of team sport, and the importance of 'old boy' networks, nor the fact that many New Zealanders significantly supplement their incomes through the mutual exchange of goods and services. Many New Zealanders also remain family-oriented from earlier days when the population was smaller, distances greater, and kinship events of more importance than they are for many today. In some respects Auckland, and to a lesser degree other urban centres, represents a pole of individualism which does not exist as strongly elsewhere in the country. Finally, young people of whatever cultural background growing up in New Zealand today keenly feel the conflict between family, peer group pressures, and 
individual aims and desires as they begin to decide which of these centres of resources they should invest in most heaviry.

In conclusion, 'adaptive strategies' are built upon a cultural base, but go beyond ethnicity, since each culture may include more than one major adaptive strategy among its members. By their typical childhood experience, Polynesians tend to be oreadapted for a Kin-Reliant or PeerReliant strategy, whereas European New Zealanders tend to be preadapted for a Self-Reliant or Peer-Reliant strategy. But all groups have some members who emphasize each of these three, and most individuals use all three strategies at different times in their lives and for different purposes.

\section{ALTERNATIVE STRATEGIES FOR OBTAINING A JOB}

As an example of the way these three adaptive strategies operate in practice, we will look at the ways one sample of New Zealand workers went about obtaining both their first and their present jobs. Some systematically checked the classified section of the newspapers, some went to the state employment office, some simply walked the streets, checking at the personnel office of any factory that interested them. A majority of European workers used this Self-Reliant strategy to obtain their first job. Occasionally a European worker had a schoolmate who put him onto the job, while the rest got help from their parents or other close relatives. 'I was shy to ask myself,' one European exclaimed, 'so Mum called in for me.'

This pattern is reversed for Polynesians. Whether New Zealand-educated Maoris and Pacific Islanders or new immigrants, the majority received help in obtaining their first job, either from friends, or far more commonly, from relatives. Among new immigrants, Kin-Reliance is the preferred strategy for about two-thirds of them.

When relatives arrive from the islands, the typical pattern is for one of their extended family members (uncles, aunts, brothers, sisters, or cousins) to take them into their homes initially, and try to find a job for them at their own place of employment. (All but one of our immigrant sample lived initially with kinsmen in New Zealand). If that fails, the host will commonly take a new migrant around himself to ask for jobs, particularly if his relative has poor
Fnglish language skills. This pattern of Kin-Reliance has potential ramifications not only for the new migrant, but for his host as well.

I was a leading hand at

When my cousin first come to New Zealand from Samoa, he can't speak much English, so my boss wouldn't give him a job. So I come up here with my cousin, going around to other factories with him. So I talked with the Personnel Officer. She said she got a job for me, but not for my cousin, because he can't speak English. I said I'd take the job here if she took my cousin. She said ok, if I worked here with my cousin . . .

Consequently, he left his well-paying and responsible job at another firm.

I explained to my old factory why I finished: I feel sorry for my cousin who can't get a job if I don't work with him. They send me a letter, want me to come back. But I told them it's too bad, too late, because they didn't get a job for my cousin. They wrote back that they have a job for my cousin. But I wrote back, "Sorry, it's too late because my cousin like this job, and me too."

When workers change jobs, however, dependence on parents or relatives for help diminishes within all three ethnic groups. By this point in life a mature adaptive pattern is being established, and relatively stable ethnic differences are emerging. Among European workers there is a substantial increase in Self-Reliance, so that this is now the clearly preferred pattern for both men and women (Table 1). But there is also an increase in reliance on friends, now mentioned by almost a fifth of the European workers of both sexes.

Of the three ethnic categories, New Zealand-educated Maoris and Islanders were the most likely to have relied on informal social networks among friends and neighbours to find their present job. Using communication channels of this kind makes it possible for Peer-Reliant workers to consider factors such as the nature of the work and working conditions which more Self-Reliant people may have little information about. The following revealing account by a Cook Islands worker illustrates the way these networks typically operate.

One of my mates (from the same island) had been working here for two 
TABLE 1

ALTERNATIVE STRATEGIES FOR OBTAINING EMPLOYMENT AMONG 157 PRODUCTION-LEVEL WORKERS

\begin{tabular}{|c|c|c|c|c|c|c|}
\hline & REL & ATIVE & & IEND & & LF \\
\hline & $\begin{array}{l}\text { First } \\
\text { Job }\end{array}$ & $\begin{array}{l}\text { Present } \\
\text { Job }\end{array}$ & $\begin{array}{l}\text { First } \\
\text { Job }\end{array}$ & $\begin{array}{l}\text { Present } \\
\text { Job }\end{array}$ & $\begin{array}{l}\text { First } \\
\text { Job }\end{array}$ & $\begin{array}{l}\text { Present } \\
\text { Job }\end{array}$ \\
\hline $\begin{array}{l}\text { Europeans } \\
(\mathrm{N}=30)\end{array}$ & & & & & $=0$ & \\
\hline$(N=30)$ & $43 \%$ & $20 \%$ & $4 \%$ & $18 \%$ & $50 \%$ & $62 \%$ \\
\hline $\begin{array}{l}\text { N.Z. Educated Maoris } \\
\text { \& Islanders }(N=53)\end{array}$ & $47 \%$ & $36 \%$ & $11 \%$ & $23 \%$ & $42 \%$ & $41 \%$ \\
\hline $\begin{array}{l}\text { Pacific Island Immigra } \\
(\mathrm{N}=74)\end{array}$ & $66 \%$ & $35 \%$ & $7 \%$ & $14 \%$ & $27 \%$ & $51 \%$ \\
\hline
\end{tabular}

years. I met him in the pub and he said he was going to Australia. "Is anyone taking your place at ..........?" I asked. "No." So one day he brought me to the factory to have a look. He said, "Oh yes, it's quite a clean job. You get nice overalls." "Well," I say, "it's good working over here for my health." So he took me up to the Personnel Officer and signed me up.

Among the Pacific Island immigrants in our sample, $14 \%$ got their present job through friends in this way. But the main shift has been from Kin-Reliance to SelfReliance. Over half the Pacific Islanders reported that they had obtained their present job on their own. This is a higher rate than among New Zealand-educated Polynesians, and is approaching the European norm. This finding may surprise employers (as it did us) who are familiar with Polynesian patterns of reliance on kinship. But many Islanders are clearly turning away from this strategy as they develop greater familiarity with New Zealand life. In fact, for some a shift in jobs may be a deliberate attempt to get out from under the supervision of their relatives. One young Samoan, who got his first job in a firm where two of his uncles were working put it this way: 'It was like having three bosses,' he complained. 'I just don't feel like working with relations.' So after two years here he visited another factory where some friends of his were working. "I come over and have a look and I seen them here and I got interested in the job.' So he applied for the job and nas been working there since.

This analysis illustrates three points from the previous discussion. First, ethnic group membership tends to pattern the majority of people to a preferred adaptive strategy for obtaining resources. Europeans are mainly Self-Reliant, and become more so over time. Polynesians educated in New Zealand are kin and friend oriented, and become even more Peer-Reliant with time, while Island immigrants bring with them a strong initial orientation towards using kin resources, but with a secondary and growing emphasis on Self-Reliance. Second, all three strategies can be found within all three ethnic categories, so that there is an intra-cultural variation present which would make a judgment as to what a particular Maori, European or Samoan individual will do, for example, extremely tenuous on the basis of ethnicity alone. Third, there is variation over time: people are affected by their growing experience in getting jobs and widening their network of contacts and associations.

\section{THE MEASUREMENT OF ADAPTIVE STRATEGIES}

If this approach to the understanding of variation amongst employees is going to be useful to employers, they will need some simple way to estimate the relative emphasis which a potential new worker places on each of these three major adaptive strategies. On the basis of our interviews with workers we have developed a little test of preferred adaptive strategy which is quick to administer and score (see p.89). The test is formatted in this article for self-administration so that you can try it too. For prospective employees. however, you will probably want to administer it verbally, checking the appropriate response categories yourself.

Our aim in this measure has been to sample a range of important areas within which choices among these alternative strategies can be made. We have included 
living arrangements, job choice, spare-time activities, social relationships, and the use of money. Note that this measure is based purely on behavioural patterns, and does not rely on attitude or opinion questions, which are notoriously unreliable when administered to people from other cultures.

Using similar, but more open-ended questions while we were developing this test, we found that both Maoris and New Zealand-educated Pacific Islanders in our sample emphasised Peer-Reliance more than either of the other two strategies, Cook Islanders and Samoans both emphasised Kin-Reliance, while the vast majority of Pakehas and European immigrants emphasised Self-Reliance (see Table 2). already suggested, are likely to possess does Self-Reliance. Polynesians, we have such prerequisite skills: more frequently than Europeans they have been raised in large families and co-operative, interdependent communities where a sensitivity to other people is stressed. Those Polynesians who choose to emphasise Peer or Kin-Reliance in their adult adaptation therefore value good social relations more than the typical Self-Reliant European, and invest more of their time and energy in maintaining them. These investments in 'social capital' are often poorly understood by Self-Reliant Europeans who see them as improvident. But Peer-Reliant Europeans, who share similar values, will understand the import-

\section{TABLE 2}

\section{ETHNIC SIMILARITIES AND DIFFERENCES IN STRATEGY CHOICE}

\section{Kin-Reliant}

EUROPEANS

British \& Australian Immigrants

$(\mathrm{N}=10)$

Native-born White New Zealanders

$(\mathrm{N}=20)$

N.Z. EDUCATED POLYNESIANS

Maoris $(\mathrm{N}=38)$

N.Z. Educated Islanders

$(\mathrm{N}=16)$

PACIFIC ISLAND IMMIGRANTS

Cook Islanders $(\mathrm{N}=30)$

Samoans $(\mathrm{N}=32)$
$11 \%$

$30 \%$

$42 \%$

$48 \%$

$49 \%$
Peer-Reliant

Self-Reliant

$20 \%$

$80 \%$

$24 \%$

$65 \%$

$32 \%$

$38 \%$

$50 \%$

$8 \%$

$36 \%$

$41 \%$
But all three ethnic categories had at least some members who emphasised each of these strategy types. Although there were some consistent and interesting sex differences which are too lengthy for presentation, men and women within each ethnic category presented a very similar overall pattern.

\section{IMPLICATIONS FOR WORKER ATTITUDES AND BEHAVIOUR}

Being able to identify a worker's preferred adaptive strategy should help management better understand and predict his or her attitudes and behaviour in many important spheres. We have space here to indicate only a few.

As adaptations to life, 'group-oriented' strategies such as both Kin-Reliance and Peer-Reliance require a person to have greater skill in interpersonal relations than ance of keeping up these relationships even if costly. Firm social ties of this kind can provide the same security as a savings account or an insurance policy. They are simply a different way of achieving the same goal.

These differences in background and approach to life affect what workers value most about their jobs. Kin-Reliant and PeerReliant workers, regardless of their specific ethnic background, emphasise most their relations with their co-workers when talking about what they like or don't like on the job. Furthermore, they enjoy their coworkers more than do Self-Reliant workers. Finally, they are more likely than SelfReliant workers to perceive themselves as working in a co-operative group, even when their task is organised on an individual basis. 


\section{TABLE 3}

\section{PREFERRED ADAPTIVE STRATEGY AND PERCEPTION OF THE WORK SITUATION}

$$
\begin{aligned}
& \text { Departments with } \\
& \text { Interdependent Tasks } \\
& \text { Men }(\mathrm{N}=39) \\
& \text { Women }(\mathrm{N}=30) \\
& \text { Departments with } \\
& \text { Individualized Tasks } \\
& \text { Men }(\mathrm{N}=30) \\
& \text { Women }(\mathrm{N}=39)
\end{aligned}
$$

$\begin{array}{ccc}\begin{array}{c}\% \text { Perceiving Themselves as Working in a Group: } \\ \text { Kin-Reliant } \\ \text { Peer-Reliant }\end{array} & \begin{array}{c}\text { Telf-Reliant } \\ \text { Per }\end{array} \\ 67 \% & 80 \% & 45 \% \\ 75 \% & 83 \% & 60 \% \\ & & \\ 43 \% & 42 \% & 18 \% \\ 67 \% & 67 \% & 42 \%\end{array}$

$\%$ Perceiving Themselves as Working in a Group:

A striking example of this is presented in Table 3 . In the factories which we studied, some departments required co-operative effort, whereas in others the work was organised on an individual basis. Under both conditions (and for both men and women) workers who emphasised a Kin or PeerReliant strategy in their daily lives were more likely to overlook individualistic conditions on the job and to perceive themselves as working 'in a group.' Conversely, Self-Reliant workers (whether Polynesian or European) tended to see themselves as working 'alone' even when placed in an interdependent work group.

\section{IMPLICATIONS FOR MANAGEMENT}

One of the most obvious and important implications of our research for managers is that no single employment and placement policy can be applied uniformly to all workers. Different types of workers come to their jobs through different pathways. And different types of workers will be more satisfied and probably perform better in different types of work situations. Kin and Peer-Reliant workers will be less likely to find their jobs through impersonal social agencies or to respond to newspaper advertisements, whereas Self-Reliant workers will be less likely to be found through the recommendations of friends and relatives. But most factories with a mixed operation probably need all three types of workers.

Grouns of closely-related, Kin-Reliant workers, for example, are likely to make an excellent team in an interdependent task requiring close supervision, particularly if natural authority relationships within the group can be recognised and used. This may be an excellent situation within which to place newly arrived Polynesian workers while they learn new work patterns from their kinsmen. Such groups may also be willing to perform quite routine and tedious jobs, because they ano getting major rewards from their social relationships with co-workers. This may be true even if their task is quite individualized, as long as management provides them with adequate opportunities on the job to satisfy these social needs.

Peer-Reliant workers will work well together where co-operative groups of mixed ethnic composition are required, particularly if supervision is light-handed and democratic. Again, the social rewards they receive from their work mates can often compensate for relatively uninteresting tasks, as long as management makes provision for this.

Finally, Self-Reliant workers will be attracted to more individualized tasks and particularly to those having inherent interest and variety. They often lack the social skills to work well together on highly interdependent teams and are relatively easily bored. But they may be more willing to take risks of individual judgment, initiative and responsibility.

In conclusion, our exploratory research suggests that identifying workers' preferred adaptive strategies is a feasible and useful exercise. More research is obviously needed with the Perceived Adaptive Strategies instrument to see how it relates to worker responses to different supervisory styles, to leadership potential, to performance measures for different types of tasks and different organisational conditions, and so forth. But its value is already clear as a way to go beyond ethnicity in differentiating among workers so that management can achieve a better fit between their employees' skills and predilections, their tasks, and the organisational structure within which these tasks will be performed. 


\section{WHAT IS YOUR PREFERRED ADAPTIVE STRATEGY?}

Answer these questions as if you were a NEW applicant for your present job. This is a measure of your own preferred approach to life; there are no right or wrong answers. Circle your answers to each question.

1. How did you find out about this job?
a. From a friend.
b. From my husband or wife.
c. From my parents.
d. From some other relative(s).
e. Just by myself.

2. Did you have any friends or relatives working in this company at the time you applied?
a. One or more relatives.
b. One or more friends.
c. Both.
d. Neither.

3. Who are the people who live in the same house with you? (Circle all that apply).
a. Just myself.
b. My wife/husband and/or my children.
c. My brother(s), sister(s), cousin(s).
d. One or more friends.
e. My uncle(s) or aunt(s).
f. My mother and/or my father.

4. Think about your spare-time activities during the last two weeks. Would you say that:

a. Most of these activities you did with your friends?

b. Most of these activities you did with your wife/husband and/or your children?

c. Most of these activities you did with other relatives?

d. Most of these activities you did by yourself?

5. During the last two weeks did you go and visit any of your relatives at their place? YES NO

6. When you were not at work, how many friends did you get together with or have a good talk with during the last two weeks?

a. Up to 4.

b. 5 or more.

7. How many of your relatives (who don't live in your home) did you get together with or have a good talk with during the last two weeks?
a. Up to 4 .
b. 5 or more.

8. When you have a big job that needs to be done around the house, do you usually:

a. Call on a friend who knows the work to help you out?

b. Ask your relatives to give you a hand?

c. Do it yourself or hire a tradesman?

9. When you have something to buy that costs a lot of money, do you usually:

a. Ask a relative to help you get it?

b. Save up and buy it yourself?

c. Ask a friend if he/she can get it for you cheaper?

10. During the last year, how often did you give a friend some money, or make a friendly loan to help him/her out?
a. None.
b. Once or twice.
c. Several times.

11. Do you have a savings account or belong to a thrift club?

$$
\text { YES NO }
$$

12. Do you regularly send money to help support one of your relatives, other than your wife/husband and children? YES 


\section{SCORING THE PREFERRED ADAPTIVE STRATEGY TEST}

Give yourself one point within an adaptive strategy type each time your answer falls in that column:

1.

2.

3.

4. $\quad 1$ point if: $c$ on Q.4

5. and/or yes on Q.5

6.

7.

8.

9.

10.

11.

12.

Kin-Reliant
$c$ or $d$
a or $c$
$e$ and/or $f$

b

b

a

Yes
Peer-Reliant

a

$b$ or $c$

$c$ and/or d but not

e and/or $f$

a

b

a

c

c
Self-Reliant

$b$ or e

d

$a$ or $b$ but not

e and/or $f$

$b$ or $d$

1 point if: a on Q.6

and a on Q.7

C

b

Yes

TOTAL SCORES:

Each Adaptive Strategy has a possible score of up to 8 points. Most people use all three strategies for some purposes, but emphasize one or another.

\section{The Meremere Coal Gang: a study of a multi-cultural work gang}

\section{B. L. MASON and B. H. COLE*}

The coal gang at the Meremere Power Station is responsible for the handling of all coal into the Station. Some coal is delivered by train, some by truck and some by an overhead (two cable) ropeway from the open cast mine at Maramarua. The coal gang accept the raw coal and either feed it through the crushers and screens into the bunkers or feed it out to the stock pile. They are also responsible for loading the buckets at the Maramarua end of the ropeway.

The work is generally of a specialised labouring nature peculiar to this particular Power Station and not utilising skills which can be bought in from outside to any extent. The work environment is generally noisy, dusty and dangerous and in some sections, such as the ropeway, is paced in a similar fashion to an assembly line. So long as the Power Station is running the coal gang must work to keep up the sup- ply of coal to the bunkers. Coal, extra to the running requirement, is directed into a stockpile.

Normally one daytime shift with some overtime is worked during the week with a smaller staff on Saturday and Sunday. At times extensive overtime has had to be worked to build up the stockpile before the heavy winter loading. The bunkers hold enough coal to carry the station overnight

\footnotetext{
- BRIAN MASON and BRUCE COLE are respectively Personnel Officer and Senior Engineer with the New Zealand Electricity Department in Auckland. Their study was completed as part of their project work for the Certificate course in Personnel Management and Industrial Relations at the University of Auckland. Their thanks are expressed to the General Manager, NZED, for permission to publish this paper and to
all staft who helped in its preparation.
} 